\title{
La posibilidad de la incidencia
}

\section{Resumen}

El presente trabajo pretende compartir algunas reflexiones y muchos interrogantes que surgen de la práctica profesional en un quehacer cotidiano con otros. Las ideas centrales del escrito se vinculan con la necesidad de contextualización de nuestra práctica, es decir, con la ubicación en un determinado contexto socioeconómico y en un ámbito particular de intervención, que nos permita evaluar la incidencia de nuestro abordaje profesional en el marco de la concepción de sujeto a la que adscribimos.
Circunscribiéndose a un ámbito específico que interviene en el campo de la infancia -y a la luz de algunas experiencias de trabajo- se expresan inquietudes surgidas desde las escenas mismas del encuentro con niños ${ }^{1}$ atravesados por problemáticas que nos convocan, para arribar a un análisis de los dispositivos que, supuestamente, se crean para «hacer lugar»y para «habilitar».

Palabras clave

incidencia $\cdot$ insistencia $\cdot$ dispositivos

\section{Introducción}

Estas son algunas reflexiones que van surgiendo de la práctica profesional, desde uno de los tantos espacios posibles de intervención. Ámbitos que intentan ser resignificados, repensados como espacios donde las modificaciones pueden producirse.

La reconstrucción simbólica de los ámbitos desde los cuales desplegamos nuestra práctica profesional, constituye también uno de los objetivos de nuestra intervención y permite que le encontremos sentido a nuestra tarea. Al concebirlos como espacios en permanente movimiento, no estancos, surge la posibilidad de pensarlos con ciertos márgenes donde es factible otorgar alguna impronta y apelar a la invención que tuerce rumbos. En este sentido, adquiere relevancia nuestra responsabilidad en lo que hacemos y en cómo lo hacemos, ya que desde allí también tomamos decisiones que inciden en la cotidianeidad de los sujetos con los que trabajamos y por ésto no hay actos sin consecuencias.

${ }^{1}$ Utilizo el término niños en sentido genérico, incluyendo en el mismo tanto a varones como a mujeres. 
Uno de los ejes centrales del presente trabajo es la interpelación de la propia práctica al considerar que aún podemos ser más rigurosos, podemos pretender intervenciones más contundentes, más creativas y con mayor incidencia desde los lugares desde los que operamos, desde donde practicamos la idea de sujeto que portamos, más allá de ciertos contextos y momentos institucionales adversos.

\section{Contexto e Incidencia}

En la tarea por conocer y reconocer los límites y el alcance de la intervención, nos ubicamos en un ámbito de trabajo e intentamos situarnos en un contexto socioeconómico para comenzar a pensar qué es posible en el aquí y ahora.

Trabajamos en contextos de pobreza, apostamos a pequeñas modificaciones, a cambios de posición de los sujetos en esas realidades, a la posibilidad de la práctica de la autonomía y de los procesos de organización social y no resignamos la idea de que las transformaciones sociales más profundas puedan producirse en algún momento. Pero consideramos que ésto nos involucra primero en nuestra condición de sujetos sociales, protagonistas de un lugar y de un momento histórico, más allá de nuestra profesión o de nuestras investiduras disciplinares.

En este sentido, no modificamos el contexto, pero sí podemos apuntar al fortalecimiento del sujeto en ese contexto, de modo que vaya situándose desde otro lugar, que pueda construir algún soporte de relación, algo que en determinado momento amortigüe, en ese cotidiano adverso en el que se desenvuelve, caracterizado por la marginación y la exclusión.

Si pensáramos que el objetivo del abordaje, desde un ámbito específico de intervención del Trabajo Social, fuese la modificación del contexto y no la creación de condiciones para el fortalecimiento del sujeto, nuestras intervenciones no tendrían -la mayoría de las veces- ninguna incidencia.

Considero que esta posición no nos vuelve ingenuos ni cómplices. En todo caso, creemos que desde nuestro lugar algo es posible y que hay mucho por hacer a nuestro alcance. Intentar en nuestros abordajes «no sumar más de lo mismo», pretender disminuir algún nivel de deterioro y desnaturalizar las prácticas abusivas que provienen de algunos ámbitos institucionales ya es una práctica que subvierte, mientras tanto, parte del orden establecido.

Si el eje de nuestra intervención es el niño ${ }^{2}$ y su mundo de relación, con la totalidad de sus vínculos, es ese niño el que nos guía con sus referencias para el armado de alguna red. Él motoriza ese armado y por eso el entramado adquiere sentido. Trabajamos con otros, portadores de diversos saberes y no pensamos «la construcción de redes» en tanto deber ser, como abstracción o en tanto formalidad. La red se constituye en instrumento si se inserta en una estrategia de intervención con cierta direccionalidad.

Decíamos que el contexto de pobreza es el marco en el que se inscriben la mayoría de las familias con las que intervenimos. La idea de subjetividades

${ }^{2}$ Referido a la práctica profesional que desarrollo en el Area de la Niñez, dependiente de la Secretaría de Promoción Social de la Municipalidad de Rosario. 
construidas en contextos de pobreza posibilita que nuestra reflexión acerca de las situaciones problemáticas se complejice, superando las lecturas sólo de contexto -en tanto marco explicativo absoluto- que no permiten ver trayectorias singulares, historias de vida y las de individuos aislados, que conciben singularidades escindidas de cualquier contexto. Este juego dialéctico (contexto/subjetividad) nos habla de un entramado, de subjetividades construidas en la inmediatez de la sobrevivencia, en ámbitos de exclusión.

A continuación intento plasmar algunas expresiones que denotan posiciones con las que habitualmente nos encontramos en los caminos por los que transitamos y que operan como obstáculos para la construcción, al encubrir la idea de que «nada es posible» o al atentar contra la autonomía del sujeto. Cabe aclarar que estas posiciones no sólo las encontramos en «otros» con los que nos vinculamos en el escenario de la intervención, sino que también nos han atravesado, en mayor o menor medida, y en determinados momentos de nuestros procesos.

\section{a) «Si no hay demanda, hay control social»}

Por un lado, como si no se necesitaran recursos para construir una demanda y, en este sentido, creo que una de nuestras tareas fundamentales es brindar un acompañamiento que permita el surgimiento de alguna demanda allí donde todo es acto, cuerpo y vertiginosidad.

Por otro lado, como si la demanda tuviera un único modo de expresarse. ¿Qué lectura hacemos de lo que sucede alrededor?, ¿qué sentido le otorgamos a lo que transcurre y tiene que ver con el padecimiento, manifestado de múltiples maneras?, ¿qué lectura es posible?, ¿qué nuevas maneras de acercamiento construimos respetuosas de la autonomía, que nos legitimen frente al otro y que permitan algún vínculo? Se trata de las maneras que encuentra el malestar para expresarse y surgen en instancias anteriores a un «efectivo pedido», en los casos en los que éste logra producirse. También son demandas, dirigidas a un otro que pueda leerlas como tal.

b) «Hay que trascender la demanda... leer más allá del pedido concreto»

En el marco de nuestras intervenciones sociales, esta es una cuestión que intentamos incluir, darle preponderancia. A veces este planteo se convierte en una posición absoluta que pretende negarle estatuto de necesidad real a algo expresado en un pedido concreto, inicial, concibiéndolo sólo como «algo a decodificar» y no considerando lo explícito y lo implícito como juego dialéctico. Si descartamos lo manifiesto priorizando sólo lo subyacente, si desestimamos de antemano lo que se expresa, si no lo concebimos como entramado, entrelazos que adquieren visibilidad en instancias diferentes, se convierte en una posición complicada. Y es una posición complicada porque trabajamos con sujetos que viven en realidades de pobreza, con importantes niveles de vulnerabilidad, con necesidades básicas insatisfechas y en contextos de exclusión.

¿Por qué no pensar que algo de ese pedido, de eso concreto, de eso explícito es real?, tan real como nuestra necesidad cotidiana -la mayoría de las veces satisfecha- de vestirnos, habitar un espacio físico que produzca un corte con el afuera (en tanto intimidad, resguardo de las condiciones climáticas, etc.), de escoger cómo y cuándo alimentarnos, de cambiar nuestra ropa según cam- 
bia la estación del año...pequeñas elecciones diarias, hábitos inimaginables en algunos contextos.

El problema radica en no poder complejizar nuestra lectura de lo que «allí ocurre» y en no poder posicionarnos desde una lógica superadora de lo asistencial. No lograr trascender esa lógica cuando a algo de ese pedido se responde, de modo de no «aplastar al sujeto», quien es el único protagonista de su transformación.

\section{c) «Esto es generado por el sistema... hasta que no haya una transforma- ción social profunda, nada tiene sentido»}

Existen posiciones de interpelación contundente al contexto, éstas van configurando a un otro transgresor en su discurso, pero muchas veces cómplice del orden establecido en su accionar, ya que no puede operar en una realidad concreta y en consonancia con su decir, sea por comodidad o por impotencia. Su denuncia no logra plasmarse en un accionar que apunte a generar pequeñas modificaciones desde los ámbitos en los que se inserta para desplegar su práctica profesional, debido a que nada tiene sentido hasta que las condiciones y el contexto más amplio sean otros. Al no poder advertir los movimientos sutiles que surgen cotidianamente -incluso como efectos tardíos de una intervención- se generan condiciones para la aparición del malestar, de la idea de imposibilidad e incluso de la comodidad que produce el autoconvencimiento de que lo que sucede alrededor no tiene que ver con uno ni con el espacio de inserción profesional.

Posiciones de muchos actores sociales que ocupan espacios de responsabilidad social, siempre ubicándose a un «costado del camino», siempre por fuera de las estrategias de intervención construidas, redefinidas, reinventadas, desechadas, por parte de un equipo que también integran. La imagen del que «siempre se retira» cuando, reunidos en una mesa, intentamos evaluar, intercambiar posiciones, definir qué rumbo seguir frente a problemáticas complejas, andando y desandando ya que no hay certezas, equivocándonos y volviendo a empezar...estando...aprendiendo.

d) «Ya le dimos todas las oportunidades y no tomó ninguna... es su elección»

Como si pudiéramos hablar de elecciones en determinados contextos, en algunas historias de vida; en todo caso, si se insiste con la idea de que el sujeto se desenvuelve en el terreno de las elecciones, cabe la pregunta: ¿dentro de qué abanico de posibilidades eligió? Prácticas profesionales situadas desde un lugar redentor, al modo de un Dios que concede dones y oportunidades, sancionando a los sujetos que considera no merecedores de su caridad.

Entonces, ¿cómo nos situamos frente al otro?, ¿cómo caracterizamos los espacios institucionales desde los que desarrollamos nuestra práctica profesional?, ¿de quiénes son esos ámbitos?, ¿hasta cuándo apostamos al sujeto?

El problema siempre recae en el otro que no incorpora las proposiciones, que no participa de los espacios que se le ofrecen, que no responde en función de los tiempos que se le suponen y pocas veces interpelamos la propia práctica y los modos que adquiere. 


\section{e) «Violencia de las intervenciones»}

Habitualmente en las intervenciones sociales se dispone de los otros y se deciden cuestiones que atañen a la vida de los demás, desde un deber ser o desde un supuesto saber en relación a lo que «será bueno» para los otros. Se elige por los demás -sujetos de nuestra intervención-, se les suponen cosas, se los interpreta arbitrariamente y hasta se llegan a predecir sus destinos. ¿En qué lugar estamos situados para generar prácticas de este tipo?, ¿cómo nos pensamos?, ¿cómo pensamos al otro?

Se trata de «devolverle al sujeto su condición de enigma» (Frigerio, 2005). Apostar al otro, situándonos en una espera activa, deseosos de que algo suceda. Permearnos por el otro, aguardar, no dejar de sorprendernos, darle lugar a lo inesperado y otorgarle un estatuto de trascendencia.

Algunas prácticas profesionales pretenden ser respetuosas del vínculo construido con los sujetos y, sin embargo, del respeto al lazo derivan rápidamente en la apropiación de los sujetos y de los ámbitos desde los que operan, concibiéndolos como territorios conquistados donde molesta la injerencia de otros que comparten el mismo escenario de la intervención.

\section{Entre-disciplinas}

En nuestro trabajo con otros, nos encontramos definiendo estrategias con algunas disciplinas que también intervienen en lo social. En algunas situaciones, nos vinculamos con profesionales que transpolan los objetivos de un trabajo terapeútico individual al terreno de las intervenciones sociales, incluso pretendiendo que tales objetivos sean el horizonte del abordaje de un equipo interdisciplinario. Aquí no siempre nos queda claro a qué nos convocan desde algunas disciplinas. En los ámbitos institucionales públicos en los que nos insertamos, ¿en qué dimensión del sujeto se pretende intervenir?, ¿los sujetos siempre conocen y aceptan esa intervención?, ¿en el marco de un trabajo que pretende ser interdisciplinario, existe un saber que deba direccionar las estrategias de intervención?, ¿hay certezas?, ¿no hay más preguntas?, ¿ya corremos el peligro de no dudar?, ¿ hay lugar para la construcción de un saber nuevo con otros?

Abundan las interpretaciones de lo que al otro le acontece, la traducción en los términos teóricos de un determinado saber -que no es más que otro saberde lo que «le estaría ocurriendo al sujeto», pero pareciera que no hay posibilidad de construir una práctica que incida en su malestar. ¿Dirección de la cura o dirección de la intervención social?

Creo que el problema radica en la dificultad de contextualizar una práctica disciplinar, de no pensar cuál es el marco desde donde despliego mi hacer profesional, de no clarificar en qué contexto estoy situado, cuál es el encuadre y en hacer que un saber se erija sobre los demás. Esto atenta contra la riqueza de los aportes que cada uno puede realizar desde su saber. 


\section{Insistencia}

En el marco de nuestras prácticas profesionales nos preguntamos: ¿cómo seguir?, ¿qué nos sostiene allí?, ¿de dónde proviene nuestro empecinamiento? Qué es lo que nos permite resignificar los espacios cuando todo por momentos se torna caótico, rutinario y sin sentido, cuando todo alrededor se desvanece una y otra vez y volvemos a insistir.

Algo nos mantiene, algo nos posibilita esa «tarea fundamental de reposición» (Frigerio, 2004), algo fluye por algún lugar y nos retroalimenta. Evidentemente, el deseo puesto en juego y el hacer consciente, reflexiva, nuestra posición frente al otro, también contribuye.

Dejarnos interrogar por lo que acontece. ¿No son los sujetos viviendo en determinadas condiciones de pobreza lo que constituye una interpelación en sí misma? Permitir ser atravesados por esa interpelación. Lo que insiste nos orienta, si no lo acallamos, direcciona nuestra práctica y contribuye a formar nuestra posición frente a la realidad.

Planteo el concepto de insistencia aclarando que no lo concibo en el sentido de lo que genera agotamiento en el otro, es decir, en términos de una repetición monótona. La insistencia aquí es pensada en tanto intencionalidad y se refiere a las múltiples maneras creativas que se pueden inventar para seguir transitando en una dirección y no en otra. Insistencia en cuanto apelación a los variados caminos existentes y por crear para aproximarnos a un horizonte que pensamos inclaudicable.

Frente a algunas intervenciones que nos generan impotencia, en situaciones en las que parecería que los niveles de vulnerabilidad y deterioro se incrementan constantemente al tiempo que, paradójicamente, se acrecientan las intervenciones, donde la pasividad parecería ser la constante y donde resulta dificultoso generar algún movimiento que detenga ese declive. En esos momentos escépticos y desgastantes de la intervención parecería que lo único que genera algún efecto es «lo deslumbrante», «lo novedoso» y los obstáculos no nos permiten visualizar ese tiempo también como un período fértil donde cabría preguntarnos: ¿cómo propongo lo que propongo, por menos novedoso y menos deslumbrante que sea?

El desafío, en todo caso, está puesto en cómo convertir en deslumbrante y novedoso lo que tengo a mi alcance, lo cotidiano. Nos encontramos con lo mismo propuesto siempre del mismo modo. ¿Cómo trabajo con los elementos propios del mundo infantil y cómo «envuelvo» de creatividad lo que es habitual (el juego, la escuela, la relación con un adulto, el afecto)?, ¿cómo nombrar, si mi intención es que el otro recupere su condición de niño?

El encuentro con otros, el hallar un lugar, el ser tenido en cuenta, el ser cuidado, el propiciar una risa, el juego, el poder preguntar, el dar lugar a las cosas que ocurren, el devolver una pregunta frente a lo que sucede, el compartir, el acompañar, el probar, el ficcionar, el sentirse «sujetado», el saber que en un lugar se es esperado y que no es lo mismo sin él.

Continuando en esta dirección, creemos que no hay sólo estrategias «repetidas», «sin resultado», sino momentos diferentes de un proceso. Hay enunciaciones distintas, hay miradas, tonos de voz, silencios, gestos propiciadores, que generan que lo tan repetido, una y otra vez, quizás hoy ancle diferente, hoy movilice, hoy sea escuchado por primera vez. 


\section{Pensando en algunos niños}

A propósito de algunas situaciones que involucran a niños y que tienen que ver con problemáticas de violencia familiar, de explotación sexual infantil, de compromiso con el consumo de sustancias tóxicas, de importantes niveles de exposición a partir de la inclusión en circuitos delictivos, de descuido, de desafiliación, de crisis subjetivas, de situación de calle ${ }^{3}$, etc., en el nudo de nuestra práctica profesional nos interrogamos: ¿con qué tela tramar?, ¿con qué elaborar?, ¿con qué soñar?, ¿con qué construir?, ¿con qué reparar? Cuando la ficción, la fantasía, se arma con los mismos elementos de lo real, de un real que aparece compacto, sin hendiduras, infranqueable, a veces mortífero. Elementos ubicados en el mismo lugar, siempre, como inamovibles, difíciles de torcer, siempre emergiendo lo mismo, una y otra vez. Escenas, despliegue...

Poder trabajar indirectamente -en otro contexto que no sea el habitual- nociones de peligro, de espera, de riesgo, de elección, de cuidado, de confianza, nociones subyacentes a un acto, implícitas en una acción, siempre presentes, aunque no se las nomine. Compartir pequeños ritos y darle ese carácter, nombrándolos. Llamados de atención, ¿dirigidos a quién?, ¿a nosotros?, ¿qué hacemos con eso?, ¿qué nos dicen?, ¿qué nos piden?, ¿a nosotros en tanto qué?, ¿en tanto profesionales de una institución?, ¿en tanto adultos, amigos, cómplices?... en tanto «otros».

Tantas veces escuchamos y repetimos que hay que «dar la palabra al niño», «escuchar al niño», pero ¿qué hago con ésto?, ¿ qué tramitación institucional le doy a esa escucha? Pedir «a gritos» un límite, un ordenador, una mirada. Pedir un límite desafiando el límite mismo. Pedirlo hasta con marcas en el propio cuerpo, cuando el modo de realizar un pedido pone en riesgo la propia vida, cuando la forma de efectuarlo atenta contra uno mismo. ¿Qué hacer allí?, ¿cómo asistir a esa escena?, ¿cómo me pienso?, ¿en qué lugar me ubica el otro?

Estos interrogantes conducen a pensar en la importancia y en la necesidad de la existencia de espacios de participación para estas realidades de trabajo (dispositivos), ámbitos de inclusión, terrenos habilitadores, fundamentales para incorporar en nuestros procesos de intervención.

\section{Dispositivos}

¿Cómo hacer para evitar el antagonismo entre la organización necesaria de un dispositivo y el movimiento zigzagueante e impredecible de los sujetos en las situaciones que abordamos? ¿Cómo dar cabida, seguir haciendo lugar a aquéllo, con su complejidad y con su dinámica propia? ¿Cómo continuar reconociendo y creando las fisuras que hacen posible ese dar lugar cuando todo por fuera de ese espacio expulsa? Fisuras que permiten la invención.

¿Cómo y cuándo ese dar lugar implica la interpelación de todo un dispositivo? ¿Cómo ofrecer un ordenamiento que no sea control? ¿Cómo sancionar para responsabilizar sin excluir, sin violentar, sin sumar más de lo mismo? ¿De

\footnotetext{
${ }^{3}$ En relación a la «situación de calle» en la que se encuentran algunos niños, consideramos que es un fenómeno multicausal, que hay diferentes formas de «habitar la calle» y que no es «la calle en sí misma» lo problemático, sino la posición de algunos niños en ella (vulnerabilidad).
} 
qué legalidad hablamos en un dispositivo? ¿A qué otra legalidad nos referimos cuando hablamos de un dispositivo que habilite y cómo la plasmamos, cómo la hacemos acto?

La apuesta es lograr que la organización necesaria de un dispositivo -sin la cual no podría funcionar- no lo burocratice, no le impida seguir escuchando, no obstaculice la posibilidad de que algo de la singularidad emerja. Concebir los bordes como posibilidad y no como límites. Bordes que existen para ser corridos. Existen prácticas que, por el resguardo de un dispositivo, generan la expulsión del que lo interpela.

Cuando el modo que encuentra un sujeto para esbozar un signo de lo que le acontece, es la interpelación misma de lo que «le está dando lugar» en ese momento, cuando es la agresión hacia algo de lo que el dispositivo le propone, ¿cómo leer ese signo y no sólo que el dispositivo está siendo «atacado», «desbordado», «desestabilizado»? Centrarnos principalmente en lo que expresa ese acto y no sólo en el resguardo de la propia organización de un espacio. Sin ese Otro, el dispositivo no tendría razón de existir, sería un dispositivo correctamente organizado pero vacío.

Generalmente, pareciera que se torna irreconciliable el antagonismo existente entre la organización de un dispositivo y la dinámica propia de los sujetos. La mayoría de las veces los dispositivos quedan entrampados en su propia rigidez.

Existen dispositivos institucionales que exigen, como condición para una admisión, lo que para un sujeto no es posible en ese momento y que quizás constituye el motivo por el cual se encuentra ahí, planteando una demanda. Ámbitos que imponen una serie de condiciones -a modo de requisitos- justamente allí donde la ausencia de esas condiciones está generando la situación problemática en la que se está interviniendo.

Desde la tarea de acompañamiento de algunas situaciones, nos encontramos recorriendo, con otros, caminos con destinos inciertos, con trayectos extensos, con horizontes que suman más de lo mismo, es decir, con dispositivos a los que es mejor no arribar. $Y$ es entonces que nos convertimos en acompañantes de caminos largos y azarosos.

Existen caminos que no conducen a ningún lugar. Al menos al recorrerlos juntos algo de la relación se construye. Quizás la idea del dispositivo como lugar posible, sea el pretexto para transitarlos. En esas instancias parecería que nos convertimos en dispositivos nosotros mismos, en tanto instrumentos, en tanto posibilidad de lazo para el otro.

El acompañamiento se torna dispositivo en sí mismo cuando en nuestra tarea de puente, de enlace, está claro desde qué sitio partimos, pero no siempre hacia dónde caminamos, porque los ámbitos de llegada posible continúan ofertando «no lugares»y demuestran ser fachadas vacías. En esos momentos es cuando pareciera que transitáramos a la deriva, pero con la importancia de caminar con otros, haciendo lazo. Pero el lazo con uno sólo tiene sentido si posibilita el encuentro con otros después de uno, si no, sólo propiciaría el narcisismo en la intervención.

Al pensar el acompañamiento como recurso, como «artefacto», vuelvo a plantear el desafío de sancionar sin excluir, permitiendo al otro -sujeto/niñosituarse con los demás desde un lugar menos mortífero, torciendo en escenas cotidianas un destino que -aunque nunca es así- parecería determinado. 
Es posible trabajar la escena que se reitera con otros que pueden desde un dispositivo sancionar sin reprimir, ordenar sin violentar, porque la sanción fuera del mismo, lejos de todo juego, es con golpes y encierro.

¿Cómo pensarnos allí? Por momentos pareciera que brindar una legalidad, un ordenamiento, sólo implicara decirle a un niño - explícita o discursivamentelo qué está permitido hacerse y lo qué no dentro de un dispositivo, lo que será o no sancionado. Cuando el dispositivo queda «atrapado» en su propia lógica de organización, el afuera se torna caótico. Siempre el afuera será leído así desde la rigidez de un dispositivo. La realidad está en constante movimiento porque es construcción social y tendríamos que intentar darle lugar tal cual es, en los instrumentos/dispositivos que edificamos para trabajar desde allí.

\section{Trabajamos con la urgencia}

Pero...¿con qué urgencia? Con la urgencia en el sentido de aprovechar lo que en un momento inesperado movilizó, entusiasmó, inquietó, tranquilizó, ancló diferente en un niño. Esa es la urgencia de la que hablamos, porque ésto que surge a partir de la construcción de un vínculo y en un momento imprevisto, lo es sin previo aviso, sin turnos programados y sin agendas. Y quizás -reiterando la expresión- sean los efectos tardíos de una intervención constante y silenciosa, nuestra o de otros. Coyuntura impredecible, momento fecundo, ¿cómo tomarlo?, ¿cómo darle lugar ahora que sucedió?, ¿cómo encausarlo para que no sea replegado, reprimido, anestesiado por los tiempos burocráticos de un dispositivo?

Esa es la urgencia con la que trabajamos (además de otras mucho más dramáticas) pero que es interesante considerar desde la idea de un dispositivo. Algo surgió desde el Otro y no sabíamos de antemano cuándo ocurriría o si ocurriría alguna vez. Y surgió. Terreno fértil para que surjan otras cuestiones después. Insisto en tomarlo, darle lugar, para que vuelva una y otra vez, quebrantando ese lugar pasivo de destino inexorable.

Trabajamos con lo dañado, con lo no cuidado, con lo no mirado, con lo postergado, con lo excluido, con lo que no tuvo lugar -o tuvo no-lugares- con lo efímero, con los avances y los retrocesos, con el malestar, con lo frágil fragilizado.

\section{Bibliografía}

COSTA, M.; GAGLIANO, R. «Las infancias de la minoridad», en: DUSCHATZKY, S (Comp.) Tutelados y asistidos. Buenos Aires, Paidós, 2000, pp. 69-119. 